\title{
The Personal Program Plan (PPP) Reviewed: A Saskatchewan Perspective
}

\author{
${ }^{1}$ Heather R. Hayes, ${ }^{2}$ Beverley A. Brenna, ${ }^{2}$ Timothy R. Claypool \\ ${ }^{1}$ Sask. Rivers School Division \\ ${ }^{2}$ University of Saskatchewan
}

\begin{abstract}
Every country and corresponding educational systems have unique ways of administering and delivering services for students deemed to have special educational needs. Unlike our American neighbors, Canada relies on individual provinces and territories to assume their own legislative authority and develop appropriate laws, policies and programs to educate all of its students. Anchored in our Charter of Rights and Freedoms each jurisdiction develops educational systems that are inclusive in nature and consistent with the right of all of its citizens to access publically funded schools. This paper outlines one school division's attempt to pilot an innovative new Personal Program Plan $(P P P)$ design in a province with a rich history of addressing the special needs of its students. A Masters of Education student in the Educational Psychology and Special Education Department of the University of Saskatchewan's College of Education decided to focus on her home school division's pilot project. Heather Hayes utilized a semi structured questionnaire to determine how six Educational Support Teachers (ESTS) responded to this new PPP template during the 2010-2011 school year. The template employed an Understanding by Design (UbD) format and utilized Performance Tasks (PTS) to demonstrate students' understandings. Recommendations for refinement and revision emerged from the study.
\end{abstract}

\section{Introduction}

Education is a right, not a privilege. In Saskatchewan (SK), education for all PreKindergarten to Grade 12 students is a shared responsibility between the Ministry of Education and the locally elected school board. Each party has particular duties and responsibilities. The Government is in charge of the following five areas: to approve the certification of teachers; to develop school curricula and documents that support curricula; to guide instructional practices that are to be used within schools; to distribute funding to the various school divisions within the province; and finally, to create legislation to ensure the best education for all students in SK [9]. The local school division is responsible for creating partnerships between the school and the community, business arising within the school division, school division facilities, transportation, enrolled students, curriculum and instruction, as well as associated employees [12].

Teachers within each school division have many duties, but their primary responsibility is to assist with student learning related to provincially approved curricula. Students with "exceptional learning and behavioural needs" [6] may require extra attention and assistance with learning. Classroom teachers are responsible for making adjustments to accommodate diversity in student learning needs, as defined by the Adaptive Dimension [8]. Students requiring assistance beyond regular adaptations may qualify as needing "intensive supports" and be identified as a Level I or Level II Intensive Needs student [11].

\section{Identification of Intensive Needs}

A student who is identified as having Intensive Needs (IN) may have a mild, moderate or severe disabling condition in one or more Intensive Support Category, e.g., Blind or Visual Impairment, Deaf or Hard of Hearing, Intellectual Disability, Mental Health Impairment, Multiple Disability, Orthopaedic Disability, Pervasive Developmental Disorder, Physical Health Impairment, Prenatal Substance Exposure, Substance Related Disorders as well as Other Diagnosed or Undiagnosed Conditions. This multi-layered system of supports demands collaboration so that the team's decisions to match specific types of intensive supports to individual students will in effect promote their success in targeted areas. Tracking and measurement of these successes is built into the review process that is designed to occur at specific times of the school year in addition to the daily, weekly and monthly reviews of achievements, challenges and emerging learning needs.

If only students learned in a regular, linear fashion that matched the regular reporting periods set by each school division, then tracking, reporting, revising, and re-visioning students' learning goals and outcomes might become routine if not formulaic. However, students with Intensive Learning Needs(IN) are as diverse as the categories and systems used to classify them. Individual difference is the norm when it comes to IN and consequently the task of setting appropriate and attainable learning goals increases in complexity as the exceptional student's exceptionalities unfold.

Textbooks and nomothetic systems attempt to provide consumers with an overview or outline of 
diagnostic criteria and descriptors that may assist with assigning the actual diagnosis or diagnoses. But beyond these labels there lies an unmapped territory of possibilities where the limits of an individual IN student are unknown and difficult to predict. Idiopathic learning trajectories replace known milestones for traditional cognitive growth and developmental patterns. In essence, each IN student becomes a case study infused with a cornucopia of strengths, challenges and unknowns. Student diversity defies definition which ironically begs the question of how valid and reliable is a presenting diagnosis.

Social constructivists might argue that selfserving systems have created these categories to contain individuals, thus simplifying communication between professionals and presumably expediting their inevitable treatment protocols. However, seasoned professionals who pay more attention to the IN student than a corresponding label typically enter into the intensive supports planning meeting with open minds that are willing to explore possibilities rather than place barriers and limits on learning.

Typically an Educational Support Teacher (EST), also called special education teachers or resource teachers, is responsible for individual assessments, program planning, and program delivery [6]. With help from the classroom teacher, the EST fills out specific forms made available by the Government of Saskatchewan in the 2010-2011 school year labeled Impact Assessment: Identification of Students Requiring Intensive Supports [11]. According to this document, there are ten different areas that potentially influence student learning. These areas include: Learning Capacity, Current Learning Achievement, Communication, Independence/Problem-solving/Work Habits, Motor Skills/Sensory, Safety, Personal/Social Well-being, Physical Health/Medical Personal Care, Transition, and Other. The EST is to decide, from a continuum based rubric, the level that "best describes the present functioning of the student within each area" [11].

Next, the EST is to outline the "Current Sources of Support", which can range from "Frequently" to "Occasionally" to "Periodically". The different kinds of supports may involve the School Team (EST and/or Educational Assistant (EA)), the School Division Team (Consultant, Speech and Language Pathologist (SLP), Educational Psychologist, Counsellor/Social Worker, and/or Occupational Therapist (OT)/Physical Therapist), and Other Agencies and External Supports (Health, Social Services, Corrections, Public Safety and Policing, or Elders/Community Based Organizations) [11]. A formal assessment by one or more members must be completed. From there, a consultant from the school division determines whether or not a student qualifies as needing intensive supports.
Depending on the amount of Occasional and/or Frequent supports identified, the student will be identified as a Level I (Occasional School Team Support, School Division Team Support, and/or Other Agency Support) or Level II (Frequent School team Support, School Division Team Support, and/or Other Agency Support) intensive needs student [11].

Following the completion of an Impact Assessment Form, appropriate programming must be developed and recorded on the Ministry of Education's prescribed Personal Program Plan (PPP) template. According to Drasgow, Yell, \& Robinson [5], the PPP directs and monitors the student's special education program and describes the educational goals, objectives, and needs of a student, programming and placement for the student, as well as the evaluation and measurement criteria that are applicable to the student's program. Individuals who require a PPP are students whose curricular outcomes differ from those in the province at their grade level, require extensive interventions and individualized supports that go beyond the Adaptive Dimension, or have been identified as a Level I or Level II intensive needs student. Every student who may require a PPP will not necessarily be identified as requiring Level I or Level II supports, but every student who meets the criteria is expected to be placed on a PPP [10].

Although the PPP is not a legally binding document, there is the expectation that PPPs will be put into place within a school division. A PPP allows school divisions to justify their responsibility and/or position regarding the education of students with intensive needs. The Ministry has included the PPP as part of the IN process, and staffing funds are tied to the number of IN students present within a school division. A school division has both a legal responsibility to educate all students, and a moral responsibility to students and parents, and these responsibilities include cases where intensive needs are involved. Using a PPP helps school division personnel by providing a platform that encourages teamwork and focuses directly on the student with intensive needs. Most importantly, the PPP document works with students' strengths and helps to prepare them for their future, creating the least restrictive educational environment possible.

This paper will outline one Canadian school division's attempt to improve the delivery of special education services with the piloting of a new and improved PPP. Its system for setting goals and measuring and monitoring the progress of those students deemed to have intensive learning needs deviated significantly from the provincial template. The intent was to improve not only the reporting and recording of IN students' progress but also to change the manner in which the individual educational goals and objectives were articulated. 


\section{The New Personal Program Plan (PPP)}

Ideally, the PPP is a strength based document that focuses on what individual students can do, rather than what they cannot do. It builds on students' skills and commences in positions of success versus where they might be struggling. It is a tool that is used to help guide teachers' work within the zone of proximal development [9], where teachers utilize students' strengths and provide assistance in tasks that students cannot manage independently. The PPP can also be used to help plan for a student's future and ensure that the School Division offers the right kinds of services to meet the needs of the student.

Additionally, parents trust that schools will provide the best possible supports for students who require intensive supports. Regardless of demonstrated abilities, test scores or academic aptitudes, parental hopes and dreams for their child's future are intertwined with their desires for fair and equitable treatment of their child with intensive needs (IN). The PPP can be used as a tool to assure parents that their child has not "slipped through the cracks" and that supports have indeed been put into place to help their child progress in educational terms. In this capacity, the PPP also serves as a framework for communication between home and school.

In 2008, Saskatchewan Rivers School Division (SRSD) was granted permission by the province's Ministry of Education to develop and pilot a new PPP template. In doing so, the focus was on establishing a Performance Task (PT) in addition to providing SMART goals (specific, measurable, achievable, relevant, and timely) for the IN student. When developing its original PPP, the SRSD referred to the philosophy of Understanding by Design (UbD) where UbD is based on the concept of teaching for understanding [14]. In order to create a PPP that is based on the UbD structure, there are three stages the writer must go through. The first stage has the end product in mind and concentrates on the desired outcomes. A goal is established that will determine what is relevant for the student. Understandings, Essential Questions, Knowledge, and Skills will all be addressed in this section. Understandings are the "big ideas", specific understandings, and the predicted misunderstandings that a student may have in relation to the goal. Essential Questions are the questions that the student will need to work through in order to foster inquiry, understanding, and transfer of knowledge. The Knowledge and Skills pieces are what the student will acquire by working through this process as well as what they will eventually be able to apply as a result of the goal.

The second stage addresses the Performance Task and Other Evidence that the student will demonstrate to show that he or she has grasped the concept. The
Performance Task (PT) is an authentic task where the student will demonstrate his or her understandings. It should typically "describe a scenario or situation that requires students to apply the knowledge and skills acquired during the year to demonstrate their understanding in a real life situation." The PT contains the elements of a SMART goal and, as well, identifies criteria according to the acronym GRASPS (goal, role, audience, situation, product/performance, standards) [14]. The Other Evidence is simply the different ways in which a student may also display knowledge (i.e. through observation, anecdotal records, quizzes, written tests, academic prompts, homework, journals, etc.) as well as whether or not the student selfreflects on his or her learning and is able to selfassess.

Finally, the last stage is the Learning Plan. The goal here is that a definitive plan will help the student accomplish the desired goal. The acronym "WHERETO" is employed to help the developer refine particular teaching strategies: W - help the students know where they are going and what is expected; $\mathrm{H}$ - hook the student; $\mathrm{E}$ - help the student explore and experience learning; $\mathrm{R}$ - give the student opportunities to rethink and revise; E - have the student evaluate their work; T - tailor to the student's needs and individual strengths and interests; and finally, $\mathrm{O}$ - organization is key to maximize engagement and effective learning [14]. The SRSD PPP has directly included these three stages in the program plan's unique design. The revamped PPP has the end in mind (i.e. why we want the student to learn this particular concept, what we want to student to be able to do with this knowledge), works backwards from the goal (i.e. how will we get there, what skills and knowledge will the student need to be able to reach the final goal), and uses the learning plan to help guide all those involved with the student.

The SRSD process for adapting the PPP template considered carefully the Ministry's PPP guidelines and subsequently the majority of the original components were retained. For example, the SRSD PPP template incorporates the SK Ministry of Education's (2009) ten Areas of Impact that potentially have the greatest influence on student learning (Learning Capacity, Current Learning Achievement, Communication,

Independence/Problem-solving/Work Habits, Motor Skills/Sensory, Safety, Personal/Social Well-being, Physical Health/Medical Personal Care, Transition, and Other). It also incorporates the student's background and identification information, his or her strengths, needs, and current level of performance, and a standards rubric, which identifies "the desired level of performance that the student will achieve by the end of the school year" [13]. Although the SRSD PPP template may not use the same terminology, 
reference to the Ministry's categories are clearly included through the following: implementation supporters; strategies and resources; evaluation and review plans; short-term objectives; location of implement plan; reporting procedures; transition goals; and signatures of team members involved. Built into SRSD's innovative plan was an element of program evaluation.

As the designer of this study regarding the SRSD adapted PPP template, Heather Hayes was an employee who was also completing her master's degree in School and Counselling Psychology at the University of Saskatchewan. Ethics hoops and hurdles were cleared both at the university and school division levels to allow this graduate student to engage in a qualitative research project that focused on some of the key contributors to a meaningful and successful PPP. Her research participants were six Educational Support Teachers (ESTs).

\section{Responses of Special Education Teachers to Initial Implementation}

A purposeful sampling technique was utilized to ensure that a "valid representation" [7] was obtained from six Educational Support Teachers (ESTs) currently employed as special education instructors by SRSD. Additionally, the following inclusionary criteria were utilized to enhance the reliability and validity of the data collected: 1) at least two years experience as an EST; 2) previous experience with the Ministry of Education's PPP template; 3) some experience writing a PPP with SRSD's new template.

Anonymous participant participation meant that respondents were free to complete the 16 page Semistructured Questionnaire without fear of adverse consequences. Results from the six participants' surveys were analyzed using content analysis to chunk and code the data and then determine how often a particular code appeared. Six themes emerged along with several recommendations for refinement and revision of the new PPP template along with ideas for future research.

The first theme related to a team approach where both teacher and parent involvement was discussed. The second theme to emerge was around the monthly timeframe. Third, the expectation of student achievement was discussed. In particular, the rubric was analyzed at length, with participants emphasizing how this rubric was connected to student achievement. In addition, high expectations were cited as worthy in producing learning greater than what could be achieved by having relatively low expectations of students. The fourth theme related to the concept of time. Apprehensions were common regarding the amount of time expected of the participants, implementation difficulties, and the monthly commitments to addressing iterations of the PPP. The fifth theme to emerge addressed teamwork difficulties, citing the collaboration between special education teachers and classroom teachers, and the involvement of parents, as areas of concern. Finally, the steep learning curve was highlighted with respect to the structure of the PPP and the UbD format.

\subsection{The Team Approach}

ESTs unanimously agreed that they were the main facilitators of the PPP process. Participants reported that it was collaboration which truly brought meaning to their work. Team members included a range of colleagues from classroom teachers and Speech and Language Pathologists (SLPs) to Psychologists and Social Workers as well as families, legal guardians, and, where possible, the students themselves. Together these teams rallied around supporting the intensive learning needs of the students in their schools. The EST adopted a facilitator role while accountability for maintaining monthly PPP updates was a shared responsibility.

Regardless of the approach, the participants spent a similar amount of time reviewing the PPPs on a monthly basis. An obvious benefit was that student goals would be adjusted as needed with accountability for planning and implementing the PPP becoming an integral part of this team effort.

Parental input was obtained periodically during the school year. Both verbal and written summaries of their child's PPP were provided along with opportunities to provide input and suggestions for ongoing revisions to this 'living document'. Some communication challenges were encountered but participants felt that there was merit in trying to engage and include parents and guardians as much as possible throughout this process.

\subsection{Teamwork Difficulties}

No collaborative process is without its challenges. Predictably, participants outlined a few struggles in regard to working with the team. Taking primary responsibility for regularly completing and updating PPPs, ESTs were responsible for engaging teachers in these processes. Levels of cooperation varied, with some teachers perceiving certain team members as "experts telling them what to do". Some participants reported having to "bug" their teachers on a consistent basis to obtain information on how a student was doing in their classroom when this information was essential to ensure that previously designed Performance Tasks were relevant and achievable. Less resistance was noted when teachers were included in PPP development from the beginning.

Additionally, role clarification was required to mitigate misunderstandings. In some cases, ESTs 
were perceived as having the sole responsibility for PPP maintenance and revision. However, for the PPP to be a true 'living document' it was essential that classroom teachers use it as means of monitoring and supporting the IN student. Participants reported that key elements in getting teachers on board were flexible thinking as well as flexible timetables. This helped ensure that PPP updates were completed consistently while being incorporated regularly into classroom teachers' daily planning regimes rather than being perceived as separate, underutilized, 'addons'.

Similarly, engaging parental participation was an ongoing challenge. One EST reported that the PPP was too complicated for some parents who appeared intimidated by its "jargon" and UbD format. However, some sections, such as the yearlong goals, PTs, as well as the rubric section, were more easily understood and appreciated by parents. One EST reported that some parents just "nodded and signed" the document. However, other participants felt that certain sections of the PPP could be utilized as an effective communication tool. As with all forms of assistance, was deemed best to keep the primary goal in mind, which in this case is to more effectively promote positive learning experiences for IN students. It seems safe to say that ESTs perceived that everyone involved in the PPP process would rally around that objective.

\subsection{Understanding by Design (UbD) Format}

The content of the template was original, but the design of it, too, involved newer concepts that the participants needed to learn. The format was based on UbD, which some participants found to be complicated. This meant that more time was spent understanding what was expected, as completion of the template involved a complete shift in thinking. Pearl (pseudonym) indicated "More time [was spent] than previous years [on the PPP] due to the different format, learning something new; more time was spent thinking of the right wording; more time was spent trying to tie everything together such as the areas of impact, performance task, overarching understandings, and knowledge and skills; also, more time was spent trying to monitor and updating monthly". Not only did the participants need to learn the format, but so did the teachers who were not familiar with UbD. Working with newly hired teachers was much easier, as they had a greater understanding of $\mathrm{UbD}$ as a unit planning tool. Josephine (pseudonym) recommended changing the PPP format to "not include the UbD format because all the teachers [she] works with do not use this and aren't familiar with it". However, another participant reported that even when teachers were not familiar with the tool, the team was still able to go through the PPP together and have meaningful discussions about the student and his or her specific needs. Participant feedback supported the importance of infusing professional development opportunities into the delivery of such an innovative approach to special education services within a school setting.

More time was spent on the new PPP because of unfamiliarity with UbD and the new PPP template itself. It was felt that the participants had less time to work directly with the students as more time was spent on understanding the $\mathrm{UbD}$ format, the PPP template, and completing the paperwork. Overall, use of the new PPP template and design was a learning curve for the participants and therefore more time consuming.

\subsection{Time for Change}

Timing is everything when it comes to successful implementation of a new initiative that has the potential to affect the hectic daily lives of educators. Providing adequate in-service training prior to as well as during the implementation of Saskatchewan Rivers School Division's (SRSD) UbD inspired PPP template helped ensure that change-related challenges would be addressed proactively.

While monthly collaborations kept the PPP 'alive' and relevant, these formal reviews and planning sessions prompted some participants to comment that more flexibility was needed in scheduling interdisciplinary meetings. In some cases, meeting every second month was assessed to be adequate rather than expecting the three to five hour monthly commitment that was reported by some of the study participants.

Overall, the participants felt that more time was spent on developing, implementing, monitoring, and reviewing progress updates than with the previous template. However, regardless of the amount of time that it took, the majority of the participants (four out of six) thought that the new PPP was an effective planning tool with an appropriate period of time devoted to its implementation. ESTs believed that this template allowed for student programming to be a collaborative process as well as allowing for goals to be broken down into smaller segments. These essential elements served to ensure accountability within the team, and to monitor regularly progress toward yearly goals. Additionally, Performance Tasks (PT) designed to ensure that the achievement of short-term goals would pave the way for subsequent successes. The fact that this collaborative effort may have required additional time commitments when compared to previous experiences with PPP development and monitoring, was mainly viewed as a secondary consideration. Regardless of the amount of time it took and work it created for the EST and classroom teacher, the study participants reported that student programming was 
more relevant and responsive with the new design expectations.

\section{Recommendations}

Previous related research in Saskatchewan found that the PPP was perceived as being ineffective [4], which included criticisms towards it being poorly written, a confusion of responsibilities, lack of consultation with the classroom teachers, goals and objectives that were not measurable or attainable, as well as an ineffective use of time. Dollar [4] pointed to the teacher's workload as the main causal factor for the PPP's malaise. This is bitter irony when the PPP is desired as an answer to perceived problems as opposed to part of the cause of problems. Related themes emerged from Demman's [3] research and include the following: the need to be flexible with parents; resource room teachers having large workloads that had a negative impact on their ability to developing effective PPPs; EAs not being able to attend PPP meetings even though they are often given the responsibility of working closing with the IN student requiring the PPP; the need for rubrics to be discussed within the context of a PPP meeting; having different knowledge bases and levels of expertise represented in a PPP team which threatened to thwart effective communication; using visual aids during the PPP meeting; and working with the dual role of resource room teacher and Vice Principal--a common hybrid position in some of the smaller rural schools in the province.

There was some consistency between the current research findings and those of Demmans [3] and Dollar [4]. Perhaps more interesting is the fact that some previous patterns and issues were not evident in this current study. For example, the current PPP template was a 'living document' with Performance Tasks (PT) that were to be reviewed monthly. These goals and objectives were constantly monitored to see if they were attainable. Unlike previous PPPs where "periodic" review was more loosely interpreted and may have translated into this frequently filed document to be reviewed on a less regular basis if at all. The new PPP incorporated a rubric into the main sections of this document so that it aligned directly with the correlates of student achievement that had been envisioned.

A lack of consultation with classroom teachers also does not seem to be an issue as a result of the process the SRSD has implemented. Consultation occurs regularly on a monthly basis and the team approach that is implemented has the expectation of both teacher and parent involvement. As far as the PPP being an "ineffective use" of time, it is actually just the opposite. Although the monthly time frame had both pros and cons, it was far from an "ineffective use" of time. The amount of time expected of the participants was rated as considerable, with one PPP reporting to take anywhere from three to eight hours to develop, and more time, again, spent on monitoring, implementing, and reviewing each PPP. Although time consuming, participants found meaning in this work. They believed that the template had important purpose in the life of a student, that it should be used as a living document, that it encouraged collaboration with the team, and that it focused positively on student progress.

Previous research reported some confusion with responsibilities. The new template seems to have alleviated this issue to some extent, as there is an identified section on the template that identifies direct lines of accountability. Frustrations do, however, still occur at times in respect to the ownership of the template as well as when working with parents. As previously found in the research, ESTs still need to be flexible with parents. Teamwork difficulties were outlined as an issue when working with both teachers and parents, but with that being said, both parents and teachers are an important part of the team and are key stakeholders within the collaboration process. Unlike past concerns, the EAs are welcome to attend the PPP meetings and different knowledge bases and levels of expertise should be represented in the PPP team.

Another main concern outlined in previous data has been the large workloads of resource room teachers. The current template increases the tensions of not having enough time within a day to get everything accomplished that needs to get accomplished, with students, teachers, parents, EAs, and administration all demanding a piece of an EST's time. Difficulties surrounding implementation and the monthly time commitments were of main concern to the participants, as well as the time it took for them and classroom teachers to learn the new format. But regardless of these findings and concerns, the majority of the participants would continue using the new template because they believed in it.

Having high expectations of achievement of student success is an underlying philosophy of the PPP. This belief seemed to shape the goals of the PPP and expectations of the student. Having high standards helps drive the participants and teachers through the entire process. However, if goals are set either too high or too low, this may impact the motivation of the student. Ultimately, there needs to be sensitivity towards and training regarding zones of proximal development [2] [15]. Providing appropriate and necessary scaffolding to ensure success with individual PTs demands knowledge of current functioning in addition to a host of related factors that may impact students' motivation and feelings of self-efficacy. The collaborative approach demonstrated by the majority of research participants 
helps to ensure that a fuller, more realistic view of the student in question is developed. Together, multiple perceptions generate a host of possible goals which may later turn into those scaffolded PTs within the new PPP template.

Continual revision by the EST was listed as a positive element of the PPP. Time was taken to continually make adjustments to enhance the document to assist the student in attaining goals. Flexibility is therefore a key piece of the picture, which was apparent from the beginning. Depending on the needs of the student, there is the choice to place a student on a PPPI (for those who follow regular curriculum but have behavioural issues) or on a PPPII (for those not able to follow regular curriculum). By having high expectations, flexible thinking, and a living document, the PPP can specifically be tailored to meet the needs of students who have special needs.

Participants offered recommendations to improve the SRSD PPP template. Suggestions were made in regards to the technical side of the template, workload expectations, time commitments, parent involvement, specific sections of the PPP, and provincial standards.

With the previous template, requirements regarding documentation were perceived as easier. An accommodations checklist was given to the teachers to fill out at the beginning and end of the school year. This not only helped with collaboration between the past and new classroom teacher, but it assisted the teacher with knowing where to begin and provided further ideas of what could be tried with the student. If such a checklist could be added to the new template, this could help support collaboration and student transition.

Sharing the workload would help reduce some of the stress expressed by participants. Increasing numbers of IN students translate into more demands placed on ESTs to ensure PPPs are completed and regularly reviewed. Additionally, with more classroom teacher involvement, ownership of the PPP would be shared along with some of the more clerical yet essential functions related to maintenance of this 'living document'.

The saying, "You can't teach an old dog new tricks" may have its roots in an 18th century proverb [1] but it continues to have idiomatic relevance in 21 st century research. Overwhelmingly, the need for increased awareness of and facility with UbD in the new PPP template emerged as a priority. It was recognized that newly minted teachers were more familiar with this concept and often had experience with it from their recent training programs. More resistance to change was reported when ESTs were working with experienced teachers. However, both veteran teachers and ESTs may have a 'change of heart' if the perceived benefits of adopting an innovative, technologically-driven PPP outweigh the anticipated effort required to sustain the 'tried and true' familiar system used to plan for and assist IN students.

It is hard to believe these professionals would prefer a disjointed accountability-driven document to a collaborative means of creatively and actively meeting students' special learning needs. By applying the UbD philosophy, innovative administrators and school division leaders alike will start with the end goal front and center when strategically planning professional development opportunities for their personnel. SRSD took the lead in Saskatchewan in terms of adapting provincial documents to meet local needs. Will other school divisions follow?

In addition to demonstrating innovative thinking and measured risk-taking by designing a divisionbased personal program planning document, SRSD also took the lead in allowing its ESTs to participate in outside research related to this planning document. Such research is important in refining school-based practice and rare in terms of school system initiatives. How classroom teachers view their role related to the school inclusion of students with special needs, and what responses parents have to school division planning documents and processes related to special education, are two topics worthy of future study. Research which focuses on teamwork barriers experienced by classroom teachers would be extremely helpful in further refinement of the manner in which we serve students with exceptional educational needs.

\section{Post Research Developments}

Heather Hayes successfully defended her thesis in January 2012 and her findings were presented at the Ireland International Conference on Education (IICE) held in Dublin, April 2012. Although SRSD and its innovative redesigned PPP template cannot take direct credit for subsequent changes to the provincial PPP template, it is worth considering that some influence may have indirectly taken place. Perhaps those interested in investigating further may direct themselves to more recent Ministry of Education publications that outline more current parameters of what are to be considered intensive supports':

http://www.education.gov.sk.ca/IntensiveSupports. The PPP acronym has changed to IIP, standing for Inclusion and Intervention Plan. On the surface this may appear to be more of a semantic than substancerelated change but taking the time to venture further into the Ministry's website offers a detailed explanation of an IIP and how it is designed to be both specific and measureable but also reviewed collaboratively by the team members. A cursory review of their descriptions of the IIP is reminiscent of Heather's study of the SRSD's new PPP template. 
There are elements that are similar yet the overall design remains more like previous provincial PPP iterations. Still there is a call for increased levels of collaboration and more regular review of IIP's specific goals and objectives.

More importantly in terms of significant change, there was recognition that the previous provincial PPP template needed updating. Heather's research highlighted some of the challenges related to introducing a significant change in the PPP design and the related learning curve that ensued for those professionals intent on making this change work effectively for IN students, their teachers, as well as their families. This recent governmental response is encouraging in that it recognized some of the known pitfalls of previous PPPs, yet preserved some of its overall structure to reduce the demand on related inservice training. Future research will address ongoing questions of how to best deliver special education to those IN students who are in need of individual instruction and programming. Acronyms aside, it's the students that matter. Heather's research highlights the dedication of those ESTs in SRSD who participated in her qualitative study. One can only hope that these participants are indicative of the majority of special educators that choose this demanding yet rewarding profession.

\section{Acknowledgements}

Saskatchewan Rivers School Division is to be commended for its openness and wiliness to partner with the University of Saskatchewan through its continued support of Heather Hayes' thesis research. Rather than adopting a "closed door" policy restricting access to internal innovations and change it did quite the opposite.

\section{References}

[1] Bailey, N. Divers proverbs. Retrieved from http://archive.org/stream/diversproverbsw00bailgoog\#page /n10/mode/2up. Retrieved on March 10th, 2012 (1721).

[2] Berk, L. E., \& Winsler, A. Scaffolding children's learning: Vygotsky and early childhood education. Washington, DC: National Association for the Education of Young Children, 1995.

[3] Demmans, T. M. Teachers' perceptions of personal program plan requirements and school team collaboration. http://library2.usask.ca/theses/available/etd12232009-212750/unrestricted/T_Demmans_

Thesis_Final.pdf, 2009.

[4] Dollar, A. The personal program plan in secondary programs: An analysis of selected Saskatchewan school division practices and policies. http://library2.usask.ca/theses/available/etd-12012006-
173124/unrestricted/AlisonDollar.pdf, 2006.

[5] Drasgow, E., Yell, M., \& Robinson, T. Developing legally correct and educationally appropriate IEPs. http://rse.saygepub.com.cyber.usask.ca/cgi/reprint/, 2001.

[6] Government of Saskatchewan. Student support services personnel qualifications.

http://www.education.gov.sk.ca/SSSPQ, 2007.

[7] Morse, J. M. \& Richards, L. Readme first for a user's guide to qualitative methods. London: Sage, 2002.

[8] Saskatchewan Education. The adaptive dimension in core curriculum. Regina, SK: Saskatchewan Education, 1992.

[9] Saskatchewan Ministry of Education. Your child's education in Saskatchewan: A handbook for recent immigrants.

http://www.education.gov.sk.ca/adx/aspx/adxGetMedia.as px?DocID=2009, 2008a.

[10] Saskatchewan Ministry of Education. Personal program plans (PPP): Smart outcomes and student outcome rubrics living document. http://www.education.gov.sk.ca/adx/aspx/adxGetMedia.as px? DocID=190,211,107,81,1,Documents\&MediaID=3809 $\&$ Filename $=$ Personal+Program + Plans $+\% 26+$ Student + Outc ome+Rubrics+June+2008.pdf, 2008b.

[11] Saskatchewan Ministry of Education. 2009-2010 Impact Assessment: Identification of Students Requiring Intensive Supports.

http://www.education.gov.sk.ca/IntensiveSupports, 2009c.

[12] Saskatchewan Rivers School Division. Special education: Curriculum and instruction. http://www.srsd119.ca/boardpolicies.html, 2005.

[13] Saskatchewan Rivers School Division. PPP template. https://www2.srsd119.ca/staffroom/employeeforms/Specia 1\%20Education/pppSep2309_v4_pub_0001.pdf, 2009.

[14] Tomlinson, C.A., \& McTighe, J. Integrating differentiated instruction and understanding by design. USA: Association for Supervision and Curriculum Development (ASCD), (2006).

[15] Vygotsky, L. S. Mind in society: The development of higher psychological processes. Cambridge: Harvard University Press, 1978. 